\section{Removal of Selected Organochlorine Compounds by Ozone-based Processes}

\author{
K. Šimkovič, J J. Derco, J. Dudáš, and B. Urminská \\ Faculty of Chemical and Food Technology, \\ Slovak University of Technology, \\ Radlinského 9, 81237 Bratislava, Slovakia
}

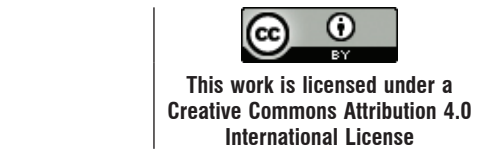

doi: 10.15255/CABEQ.2016.1025

Original scientific paper

Received: October 21, 2016

Accepted: May 31, 2017

The paper is focused on the possibility of using ozonation process combined with iron nanoparticles (nZVI - nano zero-valent iron) to remove selected specific synthetic substances, such as hexachlorobutadiene, pentachlorobenzene, hexachlorobenzene, lindane and heptachlor. Experimental measurements were performed in order to evaluate the effectiveness of the removal of substances and their removal rates. Removal of pesticides was also monitored through calculated DOC (dissolved organic carbon) as cumulative wastewater quality indicator. We investigated the effectiveness of $5 \mathrm{~mL} \mathrm{~L}^{-1} \mathrm{nZVI}$ suspension (equal to $1 \mathrm{~g} \mathrm{Fe}^{0}$ ) for the optimization of micropollutants removal from model water. Applications of $5 \mathrm{~mL} \mathrm{~L}{ }^{-1} \mathrm{nZVI}$ suspension and combined $\mathrm{O}_{3} / \mathrm{nZVI}$ processes have been shown as the most effective. Increasing concentrations of nZVI had almost no impact on the efficiency of the degradation process. Higher degradation efficiencies of $\gamma$ - $\mathrm{HCH}$ were measured in $\mathrm{O}_{3} /$ nZVI compared to the ozonation process. Degradation of pesticides HCLB, HCLBD and PCLB in all tested processes achieved efficiencies above $88 \%$.

Key words:

nZVI, organochloric compounds, ozonation, pesticides

\section{Introduction}

Safe drinking water is essential to humans and other lifeforms. However, growing industrialization and extensive use of chemicals have increased the amount of unwanted pollutants in sources of drinking water in countries all over the world. Pesticides are used worldwide to control pests in agricultural production and in many non-agricultural settings (e.g., public spaces, homes, parks, gardens, and industrial areas). The important increase in their utilization and their potentially adverse human health effects make their environmental fate a hot topic and a recurring study. The use of pesticides is becoming increasingly controversial and represents a subject to strict regulation ${ }^{1}$.

The aim of the present work was to study the degradation of five organochlorine pesticides with combined processes of ozone and nZVI. All these monitored priority substances are also known as organochlorinated pesticides (OCP) which are potentially carcinogenic, persistent, and toxic. They can be absorbed by plants, animals, as well as people. Humans and animals are exposed to them mostly through their diet, occupationally or prenatally. Over $90 \%$ of exposure comes from animal prod-

"Corresponding author: e-mail: xsimkovic@stuba.sk, tel. +421917515472 ucts due to bioaccumulation in fat tissues and through the food chain ${ }^{2}$.

Ozone $\left(\mathrm{O}_{3}\right)$ is a selective oxidant that is reactive towards double bonds, aromatic systems, non-protonated secondary, tertiary amines, and reduced sulfur species ${ }^{3}$. Ozonation is a well-established technology for water treatment, especially drinking water, and it has been the focus of attention in literature in the last few years as an option for advanced wastewater treatment ${ }^{4}$. Ozone can react with organic compounds by direct reaction as molecular ozone or by indirect reaction through the formation of secondary oxidants like free radical species. In addition, hydroxyl radicals that are formed by the decomposition of ozone also add to the oxidizing potential of the ozonation process ${ }^{5}$. It has already been shown that ozonation is effective in removing several micropollutants to more than $95 \%$ that are not typically removed during conventional activated sludge treatment, therefore making it a promising option to remove these compounds ${ }^{6}$.

Due to the reductive reaction mechanism, nanoscale zero-valent iron (nZVI) is recently one of the most extensively used nanomaterials for the remediation of contaminated soil and groundwater that mainly targets chlorinated organic contaminants including organochlorinated pesticides, polychlorinated biphenyls (PCBs), heavy metals, and 
inorganic anions? ${ }^{7}$. The interaction between nZVI and contaminants is nonspecific. In addition to the contaminant of interest, the electrons from iron oxidation are also consumed from the reduction of water $\left(\mathrm{H}_{2} \mathrm{O}\right)$ or protons $\left(\mathrm{H}^{+}\right)$to hydrogen $\left(\mathrm{H}_{2}\right)$. In order to prevent aggregation of iron nanoparticles, attachment of a stabilizing coating has commonly been applied. Many organic and inorganic stabilizers, such as anionic and nonionic surfactants, sodium carboxymethyl cellulose, starch, oils, polyacrylic acid (PAA) ${ }^{8}$, have been used to provide strong interparticle electrostatic repulsions, which overcome the attractive forces of nZVI particles towards one another.

\section{Materials and methods}

The particle size is one of the main and most important factors of nZVI. NANOFER 25 nanoparticles used in this work had the average grain size of $50 \mathrm{~nm}$. Suspension of NANOFER $25 \mathrm{nZVI}$ particles produced by NANOIRON s.r.o., Czech Republic, contains $14-18$ wt. $\% \mathrm{Fe}, 2-6 \% \mathrm{Fe}_{3} \mathrm{O}_{4}, 0-1 \%$ carbon, and $80 \%$ water. Specific surface area of these nanoparticles is larger than $25 \mathrm{~m}^{2} \mathrm{~g}^{-1}$ and specific density is in the range $1.15-1.25 \mathrm{~g} \mathrm{~cm}^{-3}(20$ $\left.{ }^{\circ} \mathrm{C}\right)$ (www.nanoiron.cz). Experiments were performed with model wastewater containing organochlorinated pesticides, i.e. hexachlorobenzene (HCLB), hexachlorobutadiene (HCLBD), pentachlorobenzene (PCLB), (1r,2R,3S,4r,5R,6S)-1,2,3,4, 5,6-hexachlorocyclohexane (common name lindane, abbreviation $\gamma$-HCH) and 1,4,5,6,7,8,8-heptachloro-3a,4,7,7a-tetrahydro-4,7-methano-1H-indene (common name heptachlor, abbreviation $\mathrm{HCH}$ ); the first three of these compounds are specified as priority hazardous substances, while all pesticides, except HCLBD, are listed in the Stockholm Convention of Persistent Organic Pollutants9.

Experiments were carried out in reactor with effective volume $2 \mathrm{dm}^{3}$ under laboratory conditions. A Life Tech ozone generator with the maximum ozone production of $5 \mathrm{~g} \mathrm{~h}^{-1}$ was used. Flow rate of oxygen was $Q_{\mathrm{O} 2}=60 \mathrm{~L} \mathrm{~h}^{-1}\left(T=21^{\circ} \mathrm{C}, p=107650 \mathrm{~Pa}\right)$ and ozone generator operated at $50 \%$ of the maximum power. Ozone was prepared from pure oxygen. The mixture of ozone and oxygen was transported to the reactor via a frit for fine bubble transfer between gas and liquid phase. The effectiveness of $5 \mathrm{~mL} \mathrm{~L}^{-1}$ NANOFER 25 nZVI suspension (equal to $1 \mathrm{~g} \mathrm{Fe}^{0}$ ) including combined $\mathrm{O}_{3} / \mathrm{nZVI}$ processes in model water was also investigated. In the process of using nZVI without ozonation was the reaction mixture of model water and nZVI homogenized by inert gas - nitrogen $\mathrm{N}_{2}$. Suspension used in the experiments was added into the reactor at the beginning of the process.

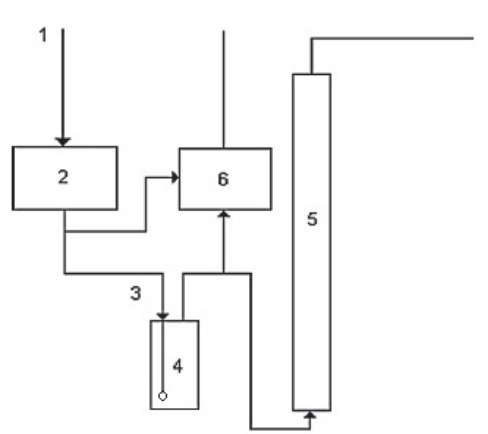

Fig. 1 - Schematic of ozonation reactor, 1 -oxygen inlet, 2 - ozone generator, 3 - mixture of $\mathrm{O}_{2}$ and $\mathrm{O}_{3}, 4$ - ozonation reactor with frit, 5 -destruction of residual ozone, 6 -detector of ozone content

\section{Analytical methods}

Quantification of organochlorinated pesticides in model water was achieved by a gas chromatographic method after liquid-liquid extraction. As the organic solvent for HPLC, $10 \mathrm{~mL}$ of n-hexane $96 \%$ p.a. (Analytika, s.r.o.) for each $50 \mathrm{~mL}$ model wastewater sample was used. The extract was analyzed by gas chromatography employing a micro-electron capture detector and column HP-5. This column is nonpolar, bonded, cross-linked and solvent - rinsable with ID of $0.32 \mathrm{~mm}$, length $60 \mathrm{~m}$ and a 0.25 $\mathrm{mm}$ film (Agilent Technologies 7890A GC Systems). All parent organochlorinated compounds used for the preparation of synthetic wastewater and standard stock solutions were purchased from Supelco Co. (Member of Sigma-Aldrich Group, USA) in high quality.

\section{Results and discussion}

The aim of this work was degradation of toxic, persistent, and potentially carcinogenic organochlorinated pesticides. For simpler comparison of removal rates of chlorinated hydrocarbons and regarding the different initial concentrations in each process, the concentration values were recalculated to DOC (dissolved organic carbon) as cumulative wastewater quality indicator. Determination of the concentration of individual pesticides in the process using nZVI was performed after 5, 15, and $30 \mathrm{~min}$. The chosen initial concentration of pollutants was $107 \mathrm{ng} \mathrm{L}^{-1}$ for HCLBD, $887 \mathrm{ng} \mathrm{L}^{-1}$ for PCLB, 738 ng $\mathrm{L}^{-1}$ for HCLB, $1592 \mathrm{ng} \mathrm{L}^{-1}$ for $\gamma-\mathrm{HCH}$ and 253 $\mathrm{ng} \mathrm{L}{ }^{-1}$ for $\mathrm{HCH}$. Organochlorine pesticides removal efficiencies are shown in Fig. 2. The highest removal rates of all pollutants were observed during the first $5 \mathrm{~min}$ of the process (Fig. 3). Treatment efficiencies of all pesticides, except $\gamma-\mathrm{HCH}$, were in this time of the process more than $96 \%$. Pesticide $\gamma-\mathrm{HCH}$ reached this efficiency in $15 \mathrm{~min}$ of the process. 


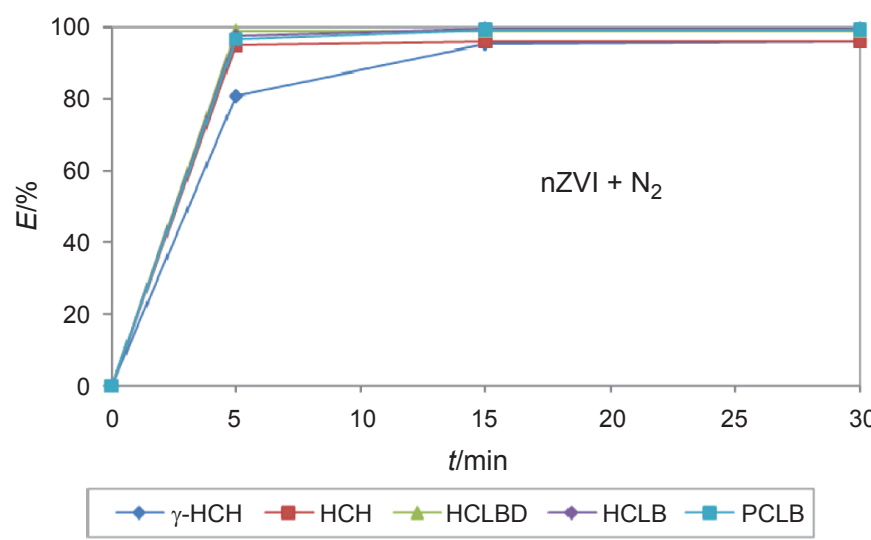

Fig. 2 - Removal efficiency of organochlorinated compounds with $n Z V I$

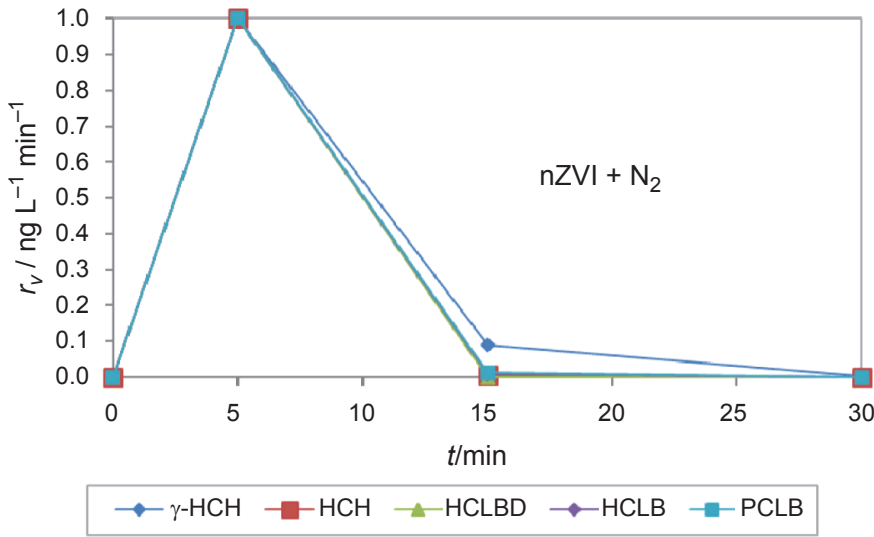

Fig. 3 - Removal rates of organochlorine compounds with $n Z V I$

Removal of the studied pesticides by $\mathrm{O}_{3}$ process is presented in Fig. 4. Determination of pesticides concertation in this process was performed after 3, 6, 10, 15, and 20 min. Lower removal efficiency (about $32 \%$ ) was observed for $\gamma-\mathrm{HCH}$ after $20 \mathrm{~min}$ of the process. At the same time, removal efficiency of $\mathrm{HCH}$ reached about $54 \%$. The highest reactivity of ozone was evident for PCLB when removal efficiency reached the highest value (97\%) after 10 min of the $\mathrm{O}_{3}$ process. Removal rates for the studied organochlorine compounds obtained by ozonation are presented in Fig. 5.

The removal efficiency of $\mathrm{O}_{3} / \mathrm{nZVI}$ process is presented in Fig. 6. Due to high degradation efficiency of nZVI particles, the selected sampling times were 4, 6, 8 and $10 \mathrm{~min}$. The highest removal rates for all pollutants were observed after $4 \mathrm{~min}$ of the treatment. The highest degradation efficiencies were observed for HCH, HCLBD and HCLB, already within $4 \mathrm{~min}$. Lower efficiency of this process is evident for $\gamma-\mathrm{HCH}(41 \%)$ ). It is obvious that the removal rates for organics using $\mathrm{O}_{3} /$ nZVI process are significantly higher compared with the re-

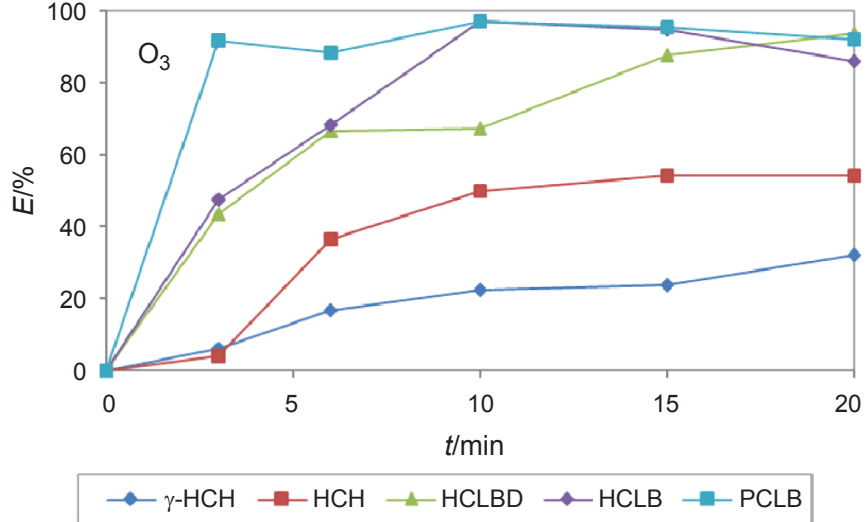

Fig. 4 - Removal efficiency of organochlorinated compounds with $\mathrm{O}_{3}$

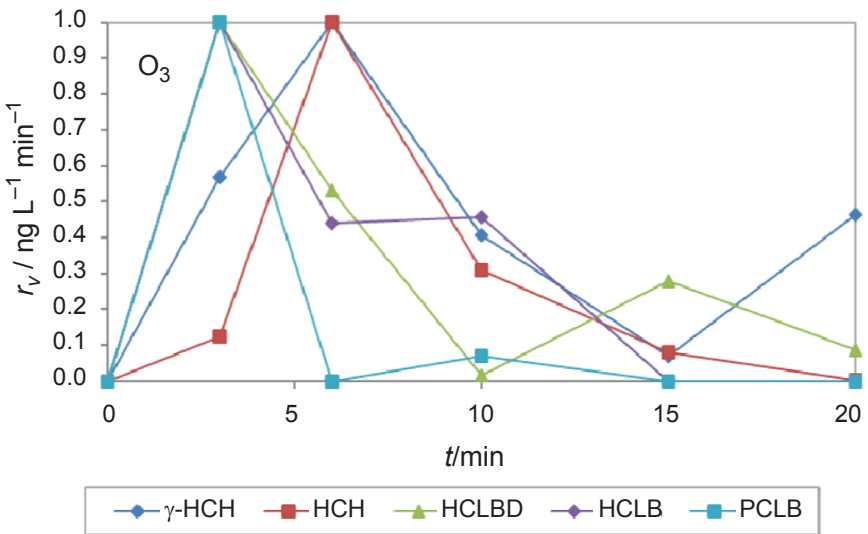

Fig. 5 - Removal rates of organochlorinated compounds with $\mathrm{O}_{3}$

moval rates achieved with ozone alone. Lindane is the most problematic compound to be removed by ozone-based processes. Higher treatment potential of individual nZVI process for removal of LIN is also evident in comparison with ozonation process - Figs. 2 and 4.

Time dependence of DOC values measured during the process are shown in Fig. 8. Part of the DOC values of $\mathrm{O}_{3} / \mathrm{nZVI}$ and $\mathrm{O}_{3}$ process were calculated so these processes could be compared to nZVI process (dashed line). Already after $5 \mathrm{~min}$, the nZVI process reached degradation efficiency of DOC 90 $\%$. Degradation efficiency in other processes failed to achieve such values as in nZVI process. In individual ozonation without nZVI, the degradation efficiencies were much lower.

\section{Conclusions}

These results indicate that nano zero-valent iron type NANOFER 25 is capable of removing organochlorine pesticides from wastewater to varying 


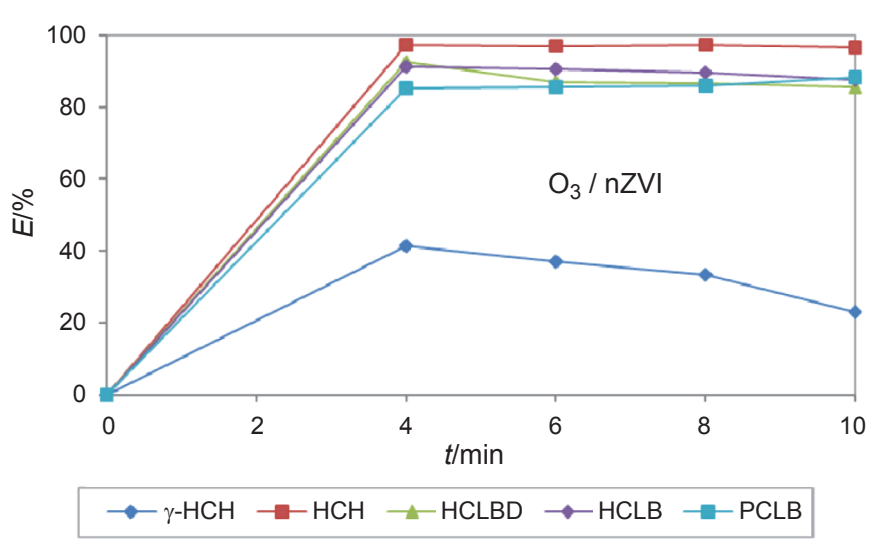

Fig. 6 - Removal efficiency of organochlorinated compounds in $\mathrm{O}_{3} / \mathrm{nZVI}$ process

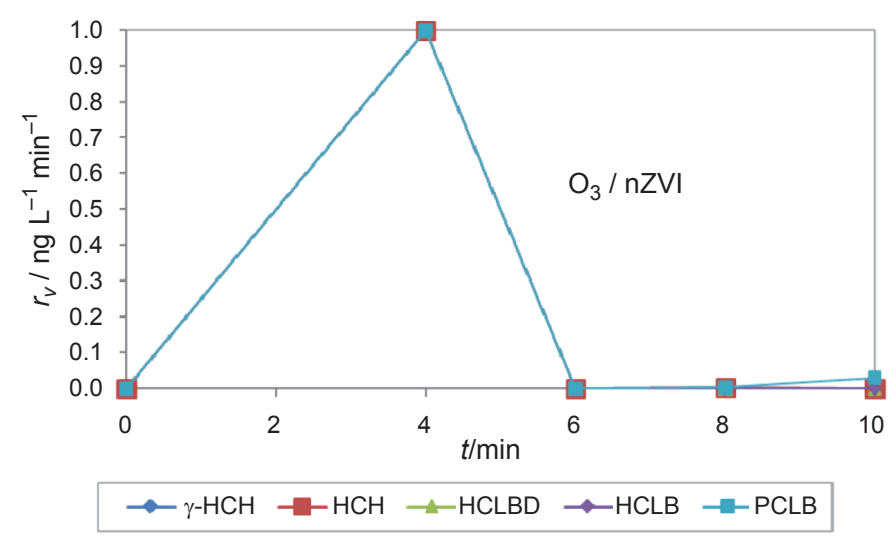

Fig. 7 - Removal rates of organochlorine compounds in $\mathrm{O}_{3} / n Z V I$ process

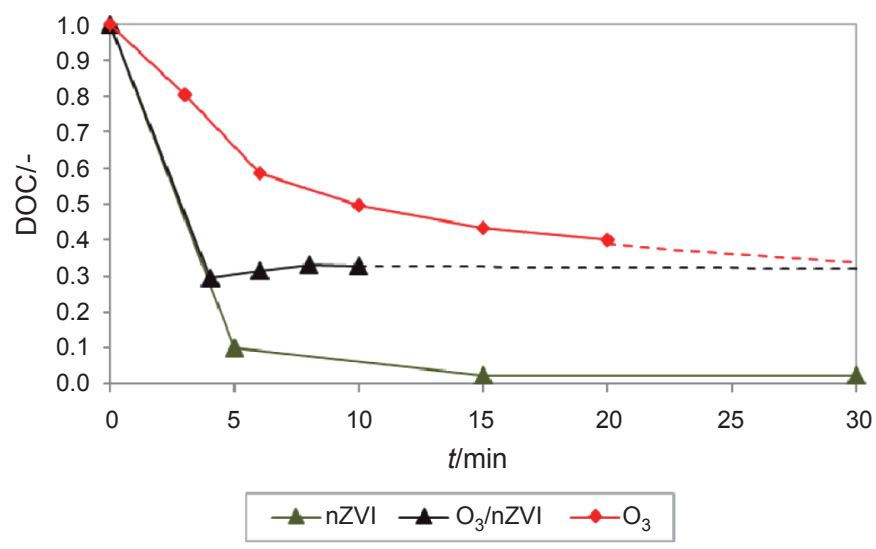

Fig. 8 -Dimensionless removal efficiency of DOC in individual processes

extents. NZVI shows very promising results regarding removal efficiency of the majority of substances. High removal efficiencies were observed for all pesticides during the first $5 \mathrm{~min}$ of the process nZVI (more than $97 \%$ ) except for $\gamma-\mathrm{HCH}$, where the same efficiency of degradation was reached in 15 min. In the $\mathrm{O}_{3}$ process, the efficiency of $\gamma-\mathrm{HCH}$ degradation was only $32 \%$ after $20 \mathrm{~min}$. Lower removal efficiency $(54 \%)$ during this reaction time was also obtained for $\mathrm{HCH}$. The highest removal efficiency ( $97 \%$ ) was achieved for HCLB, PCLB in $10 \mathrm{~min}$. The removal efficiency of HCLBD increased with the increasing reaction time. The results show that the highest removal rates were observed during the first 3-6 min of ozonation for all investigated pollutants. By combination of both processes $-\mathrm{O}_{3} /$ nZVI removal efficiency of organochlorinated compounds reached higher values in comparison to single $\mathrm{O}_{3}$ process. On the other hand, the process efficiency was lower than in case of single nZVI. Lindane was better removed in the absence of ozone. It can be concluded that the use of nZVI for the removal of synthetic organic substances is a promising option due to its easy application, high reactivity and efficiency.

\section{ACKNOWLEDGEMENTS}

This work was supported by the Slovak Research and Development Agency under the contract No. APVV-0656-12. The authors wish to thank for the support from VEGA Grant 1/0859/14.

\section{References}

1. Sustainable use Directive 2009/128/EC URL: https://www. eppo.int/PPPRODUCTS/information/2009_0128_EU-e.pdf Retrieved 2016-10-01

2. Ritter, L., Solomon, K. R., Forget, J., Persistent organic pollutants (PDF). United Nations Environment Programme (1995). Retrieved 2016-10-01. Retrieved 2016-10-21

3. Hollender, J., Zimmermann, S. G., Koepke, S., Krauss, M., Mcardell, C. S., Ort, C., Singer, H., von Gunten, U., Siegrist, H., Elimination of organic micropollutants in a municipal wastewater treatment plant upgraded with a full scale post-ozonation followed by sand filtration, Environ. Sci. Technol. 43 (2009) 7862. doi: https://doi.org/10.1021/es9014629

4. Pera-Titus, M., García-Molina, V., Baños, M. A., Giménez, J., Esplugas, $S$., Degradation of chlorophenols by means of advanced oxidation processes: a general review, Appl. Catal. B: Environ. 47 (2004) 219.

doi: https://doi.org/10.1016/j.apcatb.2003.09.010

5. von Gunten, $U$., Ozonation of drinking water: part I. Oxidation kinetics and product formation, Water Res. 37 (2003) 1443. doi: https://doi.org/10.1016/S0043-1354(02)00457-8

6. Rodayan, A., Roy, R., Yargeau, V., Oxidation products of sulfamethoxazole in ozonated secondary effluent, J. Hazard. Mater. 177 (2010) 237.

doi: https://doi.org/10.1016/j.jhazmat.2009.12.023

7. Grieger, K. D., Fjordboge, A., Hartmann, N. B., Eriksson, E., Bjerg, P. L., Baun, A., Environmental benefits and risks of zero-valent iron nanoparticles (nZVI) for in situ remediation: risk mitigation or trade-off? J. Contam. Hydrology 118 (3-4) (2010) 165. doi: https://doi.org/10.1016/j.jconhyd.2010.07.011 
8. Li, L., Fan, M., Brown, R. C., Van Leeuwen, J. H., Wang, J. Wang, W., Song, Y., Zhang, P., Synthesis, properties, and environmental applications of nanoscale iron-based materials: a review, Crit. Rev. in Environ. Sci. Technol. 36 (2006) 405. doi: https://doi.org/10.1080/10643380600620387
9. The Stockholm Convention on Persistent Organic Pollutants

doi: http://chm.pops.int/TheConvention/Overview/TextoftheConvention/tabid/2232/Default.aspx 